\title{
POSSIBLE THERMAL HISTORY OF THE MOON
}

\author{
PETER E. FRICKER*, RAY T. REYNOLDS, and AUDREY L. SUMMERS \\ Ames Research Center, NASA, Moffett Field, California, U.S.A.
}

\begin{abstract}
The possible thermal history of the Moon is investigated by means of theoretical models. The calculations include the effects of melting and time-dependent redistribution of radioactive heat sources. The known constraints can best be satisfied by a model which is characterized by relatively high initial temperatures close to the melting range; melting and, consequently, fractionation and redistribution of radionuclides would occur during the first $1.5 \times 10^{9} \mathrm{yr}$ and would then be followed by an effective cooling process. Heat flow measurements on the lunar surface should permit a distinction between such a completely fractionated model and a non-fractionated model or a model with restricted fractionation in the outer few hundred kilometers.
\end{abstract}

\section{Introduction}

In this contribution, a reconstruction of the thermal history of the Moon is attempted on the basis of theoretical models which are discussed in terms of present physical and geological evidence.

Calculations on the thermal history of the Moon have been performed for a wide range of assumed conditions by Urey $(1952,1962)$, MacDonald (1959, 1962), Kopal (1962), Levin (1962), Maeva (1964), Phinney and Anderson (1965), Fricker et al. (1967), and Reynolds et al. (in press). The results of these calculations indicate that the temperature distribution in the interior of the Moon is mainly dependent on the initial temperature, that is the temperature field upon completion of the formation of the Moon, and on the abundance and distribution of radioactive heat sources. Since these and other important parameters are uncertain, the range of possible theoretical models varies considerably. The calculations rely on the equation of heat conduction for a spherically symmetric solid body with internal heat sources

$$
\varrho C_{p} \frac{\partial T}{\partial t}=\frac{1}{r^{2}} \frac{\partial}{\partial r}\left(r^{2} K \frac{\partial T}{\partial r}\right)+A
$$

where density $\varrho$, heat capacity $C_{p}$, temperature $T$, thermal conductivity $K$, and rate of heat production $A$ are functions of radius $r$ and time $t$.

In the event of melting in the lunar interior, the subsequent thermal history will be changed. Levin (1962) accounted for the latent heat of fusion and calculated the onset of melting for a number of models. Reynolds et al. (1966) showed the importance of melting phenomena and, for purposes of calculation, defined a stage of partial melting at the melting temperature. At the stage of partial melting, the heat of fusion would be absorbed before the onset of complete melting or released before resolidification. If complete melting occurs, increased heat transfer by fluid convection could take place on a large scale; Reynolds et al. (1966) have simulated the

* Current address: Swiss National Science Foundation, 3000 Bern, Switzerland. 
limiting case of highly efficient fluid convection by removing all the excess heat energy above the liquidus into the adjacent outer radius interval.

As a consequence of melting, differentiation would set in (McConnell et al., 1967). In connection with the thermal evolution, redistribution of radioactive materials is of particular significance. Goldschmidt (1954) and others have pointed out that the principal long-lived radioactive heat sources $U$, Th and $K$, having large ionic radii, show a pronounced upward concentration in the Earth since they are rejected by the close-packed silicate lattices of the mantle. The fractionation trend of the radioactive elements in the upper layers of the Earth, in a physical environment comparable to that of the lunar interior, suggests that the interior of the Moon would also become depleted of radioactive materials if melting occurs. This suggestion is supported by the measured $\mathrm{U}, \mathrm{Th}$ and $\mathrm{K}$ contents of lunar Apollo 11 and 12 samples (Compston et al., 1970; LSPET, 1969; LSPET, 1970; Wakita et al., 1970).

A numerical procedure for investigating the consequences of fractionation by time-dependent concentration of radionuclides toward the surface was developed by Fricker et al. (1967). With the onset of melting, the radioactive heat sources U, Th and $\mathrm{K}$ start to move into the adjacent outer radius interval after an initial stage of uniform radioactive distribution. The redistribution process is described by two variable parameters, the residual fraction $R F$ and the moving factor $M F$. The residual fraction refers to the mass fraction of the radioactive isotopes retained in a given radius interval after the occurrence of partial or complete melting. The amount of radioactive isotopes in excess of the residual fraction is removed into the adjacent radius interval at a rate determined by the moving factor.

The effects of melting and fluid convection are included in the present calculations; the consequences of redistribution of radionuclides are also taken into consideration. The numerical procedure follows the outline given by Reynolds et al. (1966, in press) and Fricker et al. (1967).

The numerical values for the thermal parameters are listed in Tables I and II. The surface temperature boundary condition was held constant at $0^{\circ} \mathrm{C}$. In line with age determination for lunar material from the Apollo 11 and 12 landing sites (Albee et al., 1970, 1971; Tatsumoto, 1970; Turner, 1970, 1971) a lunar age of $4.6 \times 10^{9} \mathrm{yr}$ was assumed. The liquidus of anhydrous basalt (Cohen et al., 1967), which is very

\section{TABLE I}

Parameters for the thermal calculations

Radius, $r$
Density, $p$
Heat capacity, $C_{p}$
Lattice conductivity, $c$
Index of refraction, $n$
Opacity, $\varepsilon$
Surface temperature, $T$
Age

Radius, $r$

Heat capacity, $C_{p}$

Lattice conductivity, $c$

Opacity, $\varepsilon$

Age

$1.738 \times 10^{8} \mathrm{~cm}$
$3.34 \mathrm{~g} / \mathrm{cm}^{-3}$
$1.2 \mathrm{~J} \mathrm{~g}^{-1} \mathrm{deg}$
$7.89 \times 10^{5} \mathrm{~J} \mathrm{~cm}^{-1} \mathrm{yr} \mathrm{deg}$
1.7
$20 \mathrm{~cm}^{-1}$
$273 \mathrm{~K}$
$4.6 \times 10^{9} \mathrm{yr}$

$1.738 \times 10^{8} \mathrm{~cm}$

$7.89 \times 10^{5} \mathrm{~J} \mathrm{~cm}^{-1} \mathrm{yr} \operatorname{deg}$

1.7

$273 \mathrm{~K}$

$4.6 \times 10^{9} \mathrm{yr}$ 
TABLE II

Abundances, heat generation, and decay constants of radioactive heat sources

\begin{tabular}{|c|c|c|c|c|}
\hline \multirow{2}{*}{$\begin{array}{l}\text { Radioactive } \\
\text { nuclide }\end{array}$} & \multicolumn{2}{|c|}{ Abundance in $10^{-8} \mathrm{~g} / \mathrm{g}$} & \multirow{2}{*}{$\begin{array}{l}\text { Radioactive heat } \\
\text { generation } B_{j}, \\
\mathbf{J ~ g ~}^{-1} \text { yr }\end{array}$} & \multirow{2}{*}{$\begin{array}{l}\text { Decay } \\
\text { constant } \lambda j, \\
\times 10^{-10} \mathrm{yr}^{-1}\end{array}$} \\
\hline & Meteoritic model ${ }^{\mathrm{a}}$ & Lunar model & & \\
\hline$U^{233}$ & 1.84 & 3.27 & 2.97 & 1.54 \\
\hline $\mathrm{U}^{235}$ & 0.0133 & 0.024 & 18.0 & 9.71 \\
\hline $\mathrm{Th}^{232}$ & 5.80 & 13.16 & 0.82 & 0.499 \\
\hline $\mathbf{K}^{40}$ & 5.0 & 0.98 & 0.94 & 5.5 \\
\hline
\end{tabular}

a Urey and MacDonald, 1970 (Table 11,4)

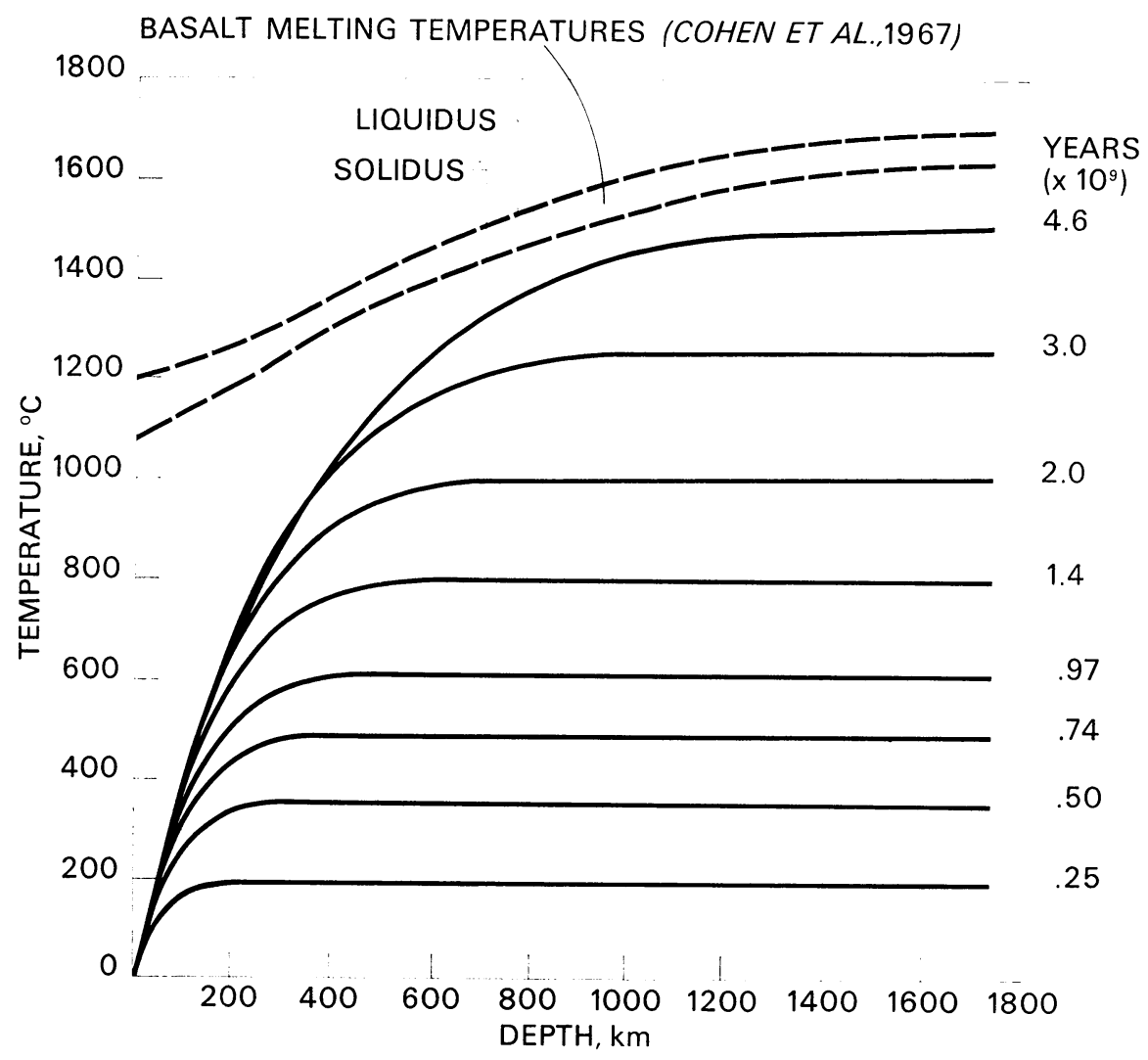

Fig. 1. Temperature distribution within initially cold solid Moon having meteoritic radioactivity (model 1). 
close to the liquidus of the Apollo 11 basalts (Akimoto et al., 1970; Ringwood and Essene, 1970) and to the solidus of peridotite (Kushiro et al., 1968), was used as the effective melting temperature (Figure 1). Two models for radioactive abundances have been considered for the present calculations (Table II). Following the estimate for the average $U$ content of the Earth's mantle by Wasserburg et al. (1964), an average initial $U$ concentration of $3.29 \times 10^{-8} \mathrm{~g} / \mathrm{g}$ was adopted for the 'lunar' model. The measured abundances of radioactive heat sources in the Apollo 11 and 12 samples were taken into account by employing a $\mathrm{K} / \mathrm{U}$ ratio of 2500 and a $\mathrm{Th} / \mathrm{U}$ ratio of 4 . The meteoritic model is based on the abundances of radionuclides in Type III carbonaceous chondrites as proposed by Urey and MacDonald (to be published). In the present models, the initial temperature distribution accounts for possible early heat contributions from accretional energy, decay of short-lived radionuclides, unipolar electric currents induced by interaction with the solar wind (Sonett and Colburn, 1968), and other short-term energy sources. The energy contribution by tidal interaction is very uncertain and has not been specifically considered. Largescale solid state convection for the Moon has been proposed by Runcorn (1962). Fricker et al. (1967) suggest that the 'cool' outer layers and the small size of the Moon relative to the Earth would minimize the effect of this process.

\section{Development of Thermal History Models}

The temperature distribution in three different thermal history models of the Moon is presented in Figures 1 to 3. For a comparison of these models with actual evidence, an important constraint provided by crystallization age analyses has to be considered; work by Albee et al. $(1970,1971)$, Turner $(1970,1971)$ and others indicates that melting of basaltic maria material at the Apollo 11 and 12 landing sites occurred some 3.3 to $3.8 \times 10^{9} \mathrm{yr}$ ago. It is likely that these basalts were formed by lava flows of internal origin (Ringwood and Essene, 1970).

Model 1 (Figure 1) shows the internal temperature distribution for a uniform Moon which has remained solid throughout its history because of the assumed low initial temperature of $0^{\circ} \mathrm{C}$. After $4.6 \times 10^{9} \mathrm{yr}$, the internal temperatures at depths of around $900 \mathrm{~km}$ are approaching the solidus of anhydrous basalt. The present surface heat flow is $9.1 \times 10^{-7} \mathrm{~J} \mathrm{~cm}^{-2} \mathrm{~s}$. Although the melting temperatures of low-melting components may be reached at a late stage, the occurrence of lava flows of internal origin some $3.5 \times 10^{9} \mathrm{yr}$ ago is not compatible with such a model. Even if an outer initially molten and fractionated layer of $200 \mathrm{~km}$ is considered for the 'cold' model, the internal temperatures after $10^{9} \mathrm{yr}$ are well below the solidus of basalt because of the efficient cooling process in the outer part of a lunar-sized body (Fricker et al., 1970; Reynolds et al., in press). One might add that the existence of a molten and fractionated outer layer at the initial stage has not been established; further age analyses of lunar samples should shed more light on this question.

In contrast to model 1, model 2 (Figure 2 ) is characterized by high initial temperature conditions. It was assumed that the Moon was melted throughout and that 


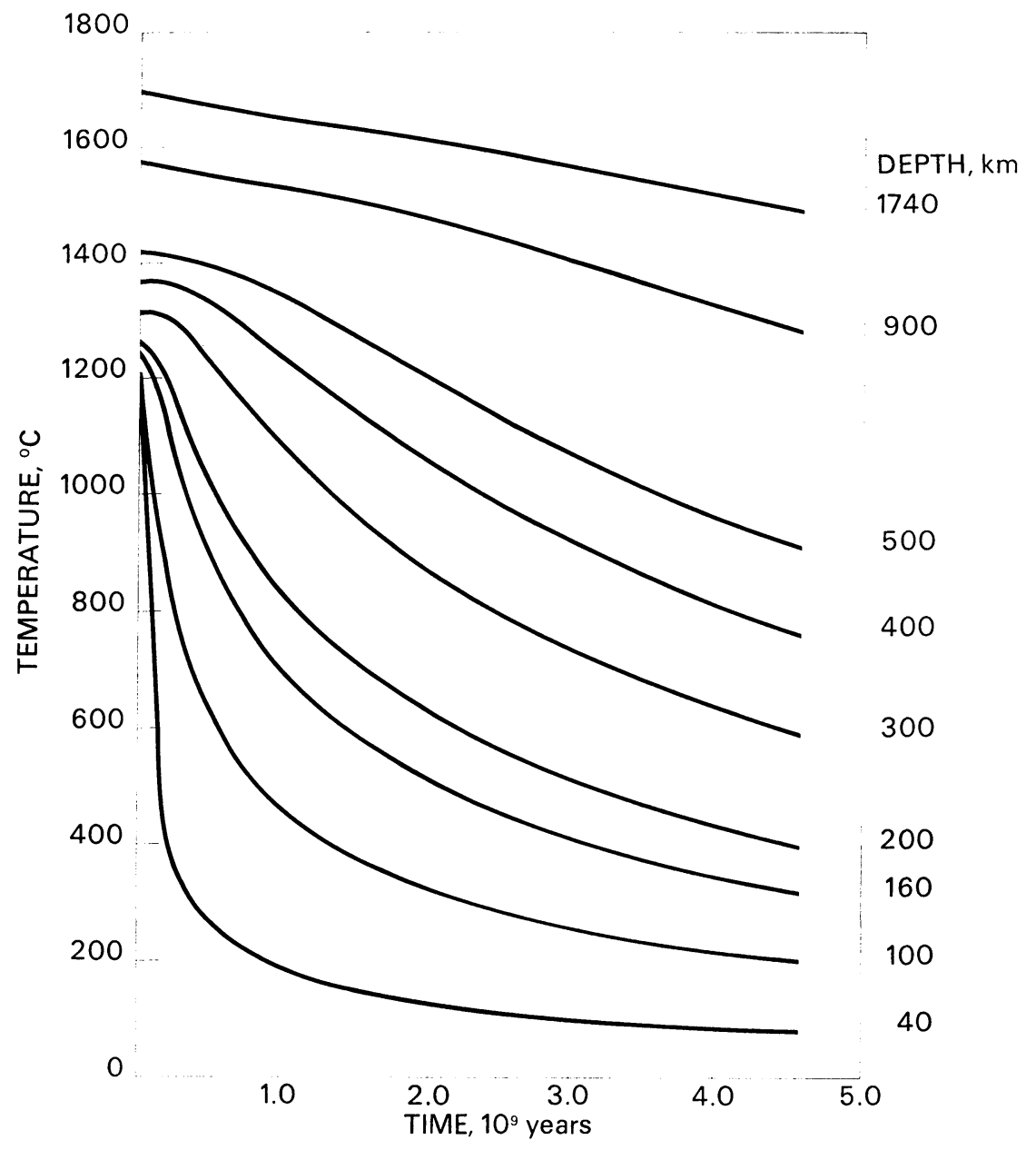

Fig. 2. Temperature distribution within initially molten and completely fractionated Moon having 'lunar' radio-activity (model 2 ).

all the radioactive heat sources were concentrated in the outermost radius interval during the period of formation. Subsequently, the outer layers are affected by a rapid cooling process. Thus it is difficult to account for the occurrence of volcanic activity 3.8 to $3.3 \times 10^{9} \mathrm{yr}$ ago. The present surface heat flow is $18.2 \times 10^{-7} \mathrm{~J} \mathrm{~cm}^{-2} \mathrm{~s}$.

Model 3 (Figure 3 ) represents an intermediate case between the initially cold model and the initially molten model. The initial temperature has been defined so that the internal temperatures reach a maximum during the presumed period of maria formation about 3.3 to $3.8 \times 10^{9} \mathrm{yr}$ ago. Wood (to be published) has recently chosen a similar approach.

A constant initial temperature of $1250^{\circ} \mathrm{C}$ was used for model 3; a near-surface melting and fractionation event at the initial stage was considered for the outer 


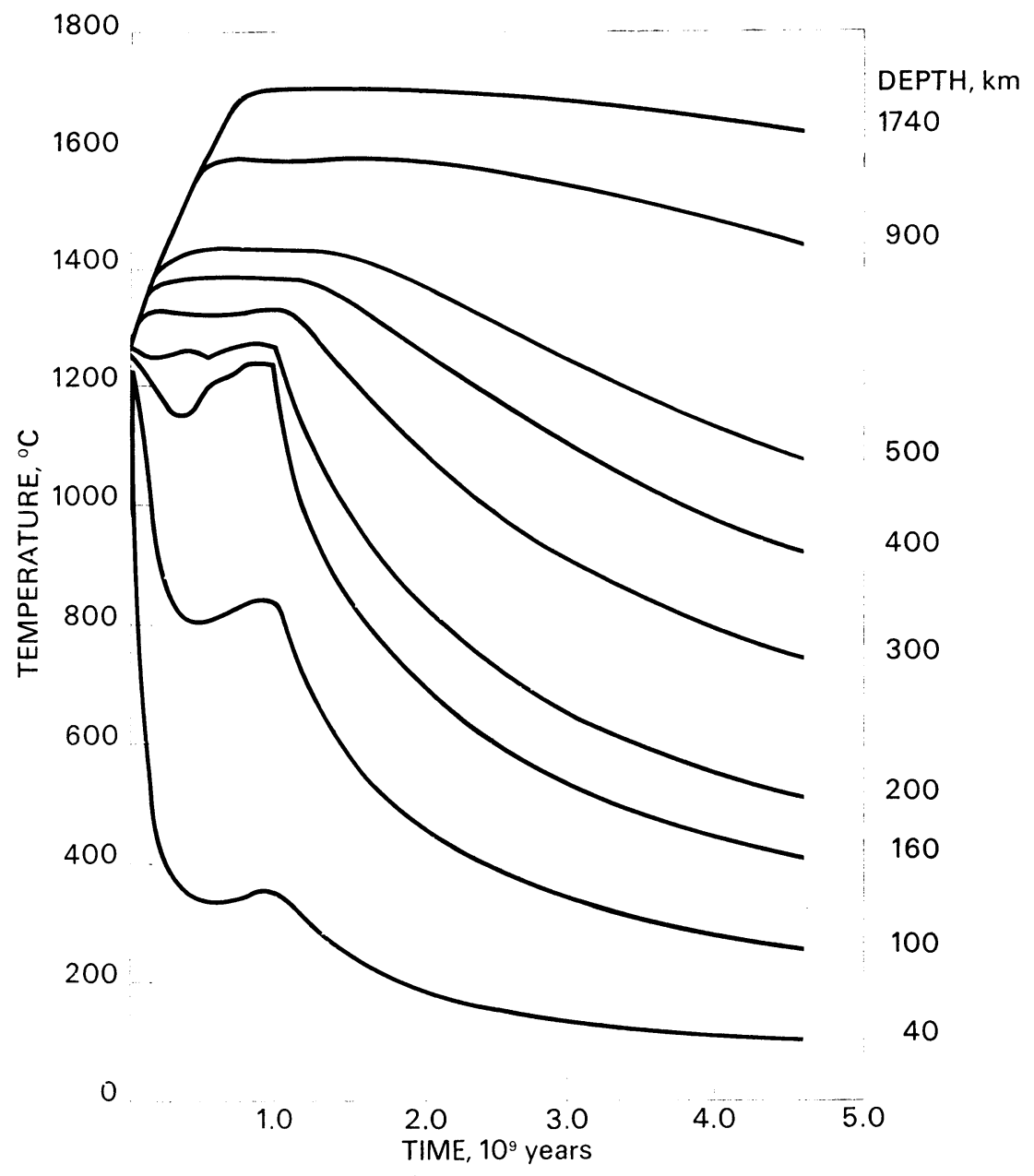

Fig. 3. Effects of melting and time-dependent fractionation of radionuclides on the temperature distribution within initially hot Moon having 'lunar' radioactivity (model 3).

$200 \mathrm{~km}$. If the internal temperatures reach the liquidus of basalt the radioactive heat sources are removed toward the surface. A residual fraction of 0.1 , corresponding to $10 \%$ of the radioactive mass fraction, was employed. In this model, the temperature maximum at depths from $200 \mathrm{~km}$ to $700 \mathrm{~km}$ is reached during the first $1.5 \times 10^{9} \mathrm{yr}$ and is then followed by a pronounced cooling period. In the outer $400 \mathrm{~km}$, the present temperatures are below $900^{\circ} \mathrm{C}$, that is less than in the 'cold' model 1 . The surface heat flow is $18.5 \times 10^{-7} \mathrm{~J} \mathrm{~cm}^{-2} \mathrm{~s}$.

\section{Discussion}

The present thermal calculations confirm that a definite solution cannot be established 
on the basis of the known data and constraints. However, the inadequacy of two extreme types of thermal history models can be shown. The uniform model with low initial temperatures (Figure 1), even with a molten and fractionated outer layer of the order of $200 \mathrm{~km}$, is not consistent with the reported occurrence of basaltic lava flows of internal origin during the period 0.8 to $1.3 \times 10^{9} \mathrm{yr}$ after formation. To a lesser degree, an initially molten and completely fractionated model (Figure 2) meets with similar difficulties. An intermediate model characterized by relatively high initial temperatures close to the melting range and by time-dependent redistribution of radioactive heat sources (Figure 3) is more consistent with the actual evidence.

It is likely, in any event, that the bulk of the Moon has been affected by melting and fractionation. The occurrence of complete melting on a large scale would have been inhibited mainly by radioactive depletion of partially molten regions and by subsequent concentration of the radioactive heat sources in the near-surface layers.

Low initial temperatures have been advocated by Urey and MacDonald (to be published) in order to explain nonhydrostatic conditions as inferred for the lunar interior from the figure and the existence of mascons. However, the amount of structural strength within the interior is uncertain (Reynolds et al., in press). It can also be noted that the present temperatures in the outer part of the Moon are lower for the intermediate model 3 (Figure 3 ) than for the uniform solid model 1 (Figure 1 ).

Clues regarding the distinction between the different possible types of thermal history models should be obtained by the planned lunar heat flow measurements. The present surface heat flow for the initially molten and fractionated model 2 as well as for model 3 with time-dependent fractionation is higher by a factor of 2 in comparison with the calculated heat flow of $9.1 \times 10^{-7} \mathrm{~J} \mathrm{~cm}^{-2} \mathrm{~s}$ for the initially low-temperature, solid model 1 , even when an initially molten outer layer of $200 \mathrm{~km}$ is considered. Thus a distinction between an initially 'cold' uniform model and an initially 'hot' or molten, fractionated model should be possible by means of heat flow determinations. The two types of fractionated models (models 2 and 3 ) could probably not be separated on this basis but additional new information from space missions should eventually permit to further delimit the number of possible solutions.

\section{Acknowledgements}

One of us (P. E. Fricker) acknowledges partial support by the Aerospace Institute Agreement between Ames Research Center and the University of Santa Clara.

\section{References}

Akimoto, S. I., Nishikawa, M., Nakamura, Y., Kushiro, I., and Katsura, T.: 1970, Geochim. Cosmochim. Acta, Suppl. 1, Proceedings of the Apollo 11 Lunar Science Conference, 129.

Albee, A., Burnett, D. S., Chodos, A. A., Eugster, O. J., Huneke, J. C., Papanastassiou, D. A., Podosek, F. A., Price Russ II, G., Sanz, H. G., Tera, F., and Wasserburg, G. W.: 1970, Science 167, 463 . 
Albee, A., Burnett, D. S., Chodos, A. A., Haines, E., Huneke, J. C., Papanastassiou, D. A., Podosek, F. A., Price Russ II, G., Tera, F., and Wasserburg, G. W.: 1971, 1971 Lunar Science Conference Abstracts, Houston, Texas, 56.

Cohen, L. H., Ito, K., and Kennedy, G. C.: 1967, Am. J. Sci. 265, 475.

Compston, W., Chappell, B. W., Arriens, P. A., and Vernon, M. J.: 1970, Geochim. Cosmochim. Acta, Suppl. 1, Proceedings of the Apollo 11 Lunar Science Conference, 1007.

Fricker, P. E., Reynolds, R. T., and Summers, A. L.: 1967, J. Geophys. Res. 72, 2649.

Fricker, P. E., Goldstein, J. I., and Summers, A. L.: 1970, Geochim. Cosmochim. Acta 34, 475.

Goldschmidt, V. M.: 1954, Geochemistry, Oxford at the Clarendon Press, p. 730.

Kopal, Z.: 1962, 'Thermal History of the Moon and of the Terrestrial Planets: Numerical Results', TR 32-225, Jet Propulsion Laboratory, California Institute of Technology.

Kushiro, I., Yoder, H. S., Jr., and Nichikawa, M.: 1968, Geol. Soc. Am. Bull. 79, 1685.

Levin, B. J.: 1962, in Z. Kopal and Z. K. Mikhailov (eds.), The Moon, Academic Press, New York, p. 157.

LSPET (Lunar Sample Preliminary Examination Team): 1969, Science 165, 1222.

LSPET (Lunar Sample Preliminary Examination Team): 1970, Science 167, 1325.

MacDonald, G. J. F.: 1959, J. Geophys. Res. 64, 1967.

MacDonald, G. J. F.: 1962, J. Geophys. Res. 67, 2945.

Maeva, S. V.: 1965, Soviet Phys. Dokl. 9, 945.

McConnell, R. K., McClaine, L., Lee, D., Aaronson, J., and Allen, J.: 1967, Rev. Geophys. 5, 121.

Phinney, R. A. and Anderson, D. L.: 1965, 'Internal Temperatures of the Moon', Minnesota University Rept., Tycho Meeting.

Reynolds, R. T. and Summers, A. L.: 1969, J. Geophys. Res. 74, 2494.

Reynolds, R. T., Fricker, P. E., and Summers, A. L.: 1966, J. Geophys. Res. 71, 573.

Reynolds, R. T., Fricker, P. E., and Summers, A. L.: in J. Lucas (ed.), Lunar Thermal Characteristics, AIAA Progress Series (in press).

Ringwood, A. E. and Essene, E.: 1970, Geochim. Cosmochim. Acta, Suppl. 1, Proceedings of the Apollo 11 Lunar Science Conference, 769.

Runcorn, S. K.: 1962, Nature 195, 1150.

Sonett, C. P. and Colburn, D. S.: 1968, Nature 219, 924.

Tatsumoto, M.: 1970, Geochim. et Cosmochim. Acta, Suppl., Proceedings of the Apollo 11 Lunar Science Conference, 1595.

Turner, G.: 1970, Geochim. Cosmochim. Acta, Suppl. 1, Proceedings of the Apollo 11 Lunar Science Conference, 1665.

Turner, G.: 1971, 1971 Lunar Science Conference Abstracts, Houston, Texas, p. 63.

Urey, H. C.: 1952, The Planets: Their Origin and Development, Yale University Press, New Haven, Conn.

Urey, H. C.: 1962, in Z. Kopal (ed.), Physics and Astronomy of the Moon, Academic Press, New York, p. 481.

Urey, H. C. and MacDonald, G. J. F.: in Z. Kopal (ed.), Physics and Astronomy of the Moon, 2nd ed., Academic Press, New York (to be published).

Wakita, H., Schmitt, R. A., and Rey, P.: 1970, Geochim. Cosmochim. Act,a Suppl. 1, Proceedings of the Apollo 11 Lunar Science Corference, 1685.

Wasserburg, G. J., MacDonald, G. J. F., Hoyle, F., and Fowler, W. A.: 1964, Science 143, 465.

Wood, J. A.: in G. Simmons (ed.), The Geophysical Interpretation of the Moon, preprint Sept. 1970 (to be published). 